\title{
Ejercicios de traición: intertextualidad, culturalismo y traducción en la poesía contemporánea española
}

Palabras clave: intertextualidad — traducción — apropiación — metapoesía - posmodernidad — culturalismo — poesía española contemporánea.

"Recordando, no a Eliot, sino una traducción de Eliot" Pere Gimferrer

\section{La imitatio contemporánea}

El legado grecolatino está presente en las letras castellanas desde la Edad Media, aunque será durante los siglos XVI y XVII cuando la imitatio se conciba no como una simple copia, sino como salto o ruptura ${ }^{1}$. La cultura grecolatina en general y su literatura en particular se entiende, desde antiguo, como un modelo a seguir: "La literatura romana [...] más que cualquier otra literatura nacional influyó en las formas y modos de pensamiento de las letras europeas posteriores"2. Fernando Lázaro Carreter señala que esta imitación literaria centrada principalmente en modelos grecolatinos anteriores, "era un principio básico e incuestionado de práctica poética"3.

${ }^{1}$ La fractura que quieren dejar patente los hombres de la época viene marcada por esa idea generalizada de la "oscuridad" adscrita al período medieval y que el humanismo contribuye a alimentar. Aun así, podemos señalar ya cierta conciencia de ruptura en las palabras que Juan de Salisbury atribuye a Bernardo de Chartres: quasi nanos, gigantium humeris insidente. I. Saresberiensis, Metalogicon, Turnhout, Brepols, 1991, III, 4.

${ }^{2}$ G. Walsh, "Epílogo", en: E.J. Keneny, W.V. Clausen (eds.), Historia de la Literatura Clásica, Vol. II, Literatura Latina, Madrid, Gredos, 1989, p. 849.

${ }^{3}$ F. Lázaro Carreter, "Imitación compuesta y diseño retórico en la Oda a Juan de Grial", Anuario de Estudios Filológicos, 2, 1979, p. 98. 
Desde mediados del siglo pasado se observa una corriente culturalista en la poesía española que, precisamente, vuelve la vista a los modelos grecolatinos $^{4}$. Esta querencia al mundo clásico guarda una estrecha relación con la sólida formación universitaria con la que todos los poetas cuentan y con el hecho de que muchos hayan sido traductores de obras latinas y griegas ${ }^{5}$. El papel que cumple el ejercicio de la traducción — como apunta Díaz de Castro- "proporciona motivos, temas, formas y figuras que determinan la creación propia mas allá de las variaciones sobre tema clásico. [...] la tradición clásica cumple un papel fundamental y sostiene aspectos de su poesía"6. Para Bourdieu, el campo de la traducción no es una mera copia del original, lleva adscritos otros elementos que permiten al poeta hacer público lo que ama y que refuerza su posición aunque sea con usos instrumentalizados ${ }^{7}$. Ahora, momento en el que la poesía contemporánea se acerca a la imitación antigua, la perspectiva poética no es la misma, ha cambiado el modelo clásico, que ya no se concibe solo como aquello que invita a la copia o a la repetición ${ }^{8}$, sino que se ve como sugerencia, como referencia de innegable validez, como una orientación reinterpretativa ${ }^{9}$. Se recupera la tradición grecolatina casi como un acto fetichista ${ }^{10}$, pero no en el sentido de desviación sexual apuntada por el

${ }^{4}$ La presencia de la tradición clásica es palpable en toda la poesía del XX (particularmente los años que comprenden el último lustro) y los años que han transcurrido en el XXI; las posturas ante los mitos y los autores de la Antigüedad reflejan y definen los posicionamientos estéticos y hasta ideológicos de los poetas. Aunque comúnmente se relaciona el culturalismo con la poesía de los novísimos (década de los setenta), no debemos restringirlo solamente a esta corriente literaria: encontramos rasgos del culturalismo de tradición clásica en los poetas anteriores (generación del 50 y el 60) y en los posteriores (décadas de los 80 y 90), hasta el punto de que el uso de los motivos grecolatinos puede ser tomado como hilo conductor que nos guía — nuevo hilo de Ariadna - por el laberinto poético de los últimos años. Precisamente, tanto el mito como el acervo de los clásicos lo son por su capacidad de dar cauce a diferentes mensajes, acomodarse a diversas estéticas, no como adorno, sino como expresión propia.

${ }^{5}$ Así, Enrique Badosa traduce a Horacio; Aurora Luque a Safo; Luis Alberto de Cuenca quizá el más prolífico - a Eurípides, Homero, Virgilio, Calímaco; y Juan Antonio González Iglesias a Ovidio y a Catulo. Cfr. F. Díaz de Castro, "La tradición clásica en la poesía española reciente: aproximaciones", en: M. A. Naval (ed.), Poesía española posmoderna, Madrid, Visor, 2010, pp. 64-65.

${ }^{6}$ Ibidem.

${ }^{7}$ P. Bourdieu, Razones prácticas. Sobre la teoría de la acción, Barcelona, Anagrama, 1997, p. 173.

${ }^{8}$ La presencia de autores clásicos en la literatura del Renacimiento solía considerarse como un elemento que infería calidad a la obra. Por encima de la originalidad se "prestigiaba la imitación cabal de modelos clásicos"; era, pues, una práctica poética extendida ensalzada por críticos, comentaristas, retóricos y preceptistas, amén de los humanistas. G. Laguna Mariscal, "La influencia de la poesía latina en la española durante el Renacimiento", en: C.M. Cabanillas Núñez (ed.), Actas de las II Jornadas de Humanidades Clásicas, Almendralejo (Badajoz), I. E. S. Santiago Apóstol D. L., 2001, p. 413.

${ }^{9}$ C. García Gual, "Cultura clásica y mundo actual”, en: L.A. Ribot García, R. Villares Paz, J. Valdeón Baruque (eds.), Año mil, año dos mil. Dos milenios de Historia de España (II), Madrid, Sociedad Estatal España Nuevo Milenio, 2001, p. 255.

10 J. Bergua Cavero, "La tradición clásica y el concepto de influencia", en: G. Fernández Ariza (ed.), Literatura Hispanoamericana del siglo XX. Mímesis e iconografía, Málaga, Servicio de Publicaciones de la Universidad de Málaga, 2003, p. 15. 
DRAE, sino con el valor del 'culto al que se atribuye poderes sobrenaturales, especialmente entre los pueblos primitivos'; quizá ese poder magnético del capital simbólico de Bourdieu: una fuerza mágica que "ejerce una especie de acción a distancia sin contacto físico" $"$.

\section{Apropiaciones posmodernas}

La cosmovisión posmoderna ${ }^{12}$ con su "indeterminación" 13 abre paso al uso de artificios compositivos que permiten que la relectura de la tradición y los elementos clásicos encuentren fácil acomodo en la lírica contemporánea española. En los procesos de cita intertextuales en general y, más concretamente, en la poesía culturalista contemporánea, el poeta puede ocultar los robos textuales ${ }^{14}$, pero lo normal es que opte por mostrar abiertamente la referencia a través del empleo de diferentes procedimientos delimitadores, como por ejemplo: el mantenimiento del idioma clásico, la demarcación gráfica con el empleo de cursiva o del entrecomillado, o el empleo del estilo directo o indirecto con verbos de dicción. Todo ello para contribuir al proceso de recepción y favorecer la "participación (re)creadora del receptor"15.

${ }^{11}$ P. Bourdieu, op. cit., p. 173.

12 Es fundamental entender que la posmodernidad no debe ser considerada como una época histórica, sino como una manera de ver la Historia presente y pasada; debe concebirse como una orientación de pensamiento compartida por creadores dispares de generaciones diversas. Tal y como reconoce Agustín Fernández Mallo: "es otra manera de 'mirar', una mirada en la que la flecha del tiempo existe pero se curva sobre sí misma, una manera que se visualiza con tal de hacer un simple cambio de sistema de referencia (de absoluto a relativo), sistema de referencia centrado en otro concepto de tiempo: el Centro de Tiempos". A. Fernández Mallo, Blog up, ed. de T. Gómez Trueba, Valladolid, Universidad de Valladolid, Secretariado de Publicaciones e Intercambio Editorial, 2012, p. 96. Así pues, la posmodernidad ha de ser tratada como procedimiento de descubrimiento, la conciencia "debe adoptar otro modo de ver, de sentir, de constituirse, ya no de ser, sino de sentir, de hacer". A. Vásquez Roca, "El hipertexto y las nuevas retóricas de la postmodernidad. Textualidad, redes y discurso ex-céntrico", Philosophica, Revista del Instituto de Filosofia, 27, 2004, p. 153.

13 El término de "indetermanence" es el neologismo resultante de los dos conceptos principales sobre los que se asienta la posmodernidad: la "Indeterminación" y la "Inmanencia", originadas ambas en las artes de Marcel Duchamp. Cfr. I. Hassan, "Culture, Indeterminancy and Immanence: Margins of the (Postmodern) Age", Humanities in Society, 1, 1978, pp. 51-85. Del mismo, The Right Promethean Fire: Imagination, Science and Cultural Change, Urbana, University of Illinois Press, 1980, p. 269. Del mismo, "Pluralism in Postmodern Perspective", Critical Inquiry, vol. 12, 3, 1986, pp. 503-520; véase también J. F. Lyotard, Les transformateurs Duchamp, Paris, Éditions Galilée, 1977, p. 95.

${ }^{14}$ Nos referimos al "criptoculturalismo". Guillermo Carnero lo concibe como aquel en el que las referencias culturales - externas o internas - no están señaladas, sino que se encuentran insertas en el poema sin ningún rasgo diferenciador, es decir, el poeta asume como suyos textos ajenos que introduce en sus poemas sin marca señalizadora alguna. Cfr. G. Carnero, "Cuatro formas de culturalismo", Poesía Española Contemporánea, Biblioteca Virtual Miguel de Cervantes, 2005, <http:// www.cervantesvirtual.com/obra-visor/cuatro-formas-de-culturalismo-0/pdf/> 10 de marzo de 2016.

15 A. Mendoza Fillola, El intertexto lector. El espacio de encuentro de las aportaciones del texto con las del lector, Cuenca, Ediciones de la Universidad de Castilla la Mancha, 2001, p. 19. 
José Antonio Martínez Muñoz (Murcia, 1959), en un proceso recreativo, reflexiona sobre el valor de la cita intertextualizada, que además traduce y adapta. Nos enfrentamos a varias inclusiones del intertexto en un único trabajo poético. En este "Ejercicio de traición", como un moderno Pierre Menard, medita en alto sobre la apropiación y sus consecuencias; dedica "sus escrúpulos y vigilias a repetir en un idioma ajeno un libro preexistente" 16 :

Dice Anacreonte de Teos:

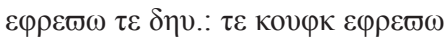

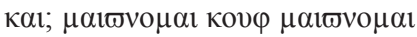

Y no sé qué significa.

Pero — los dioses lo bendigan— Juan Ferraté

traduce:

Otra vez quiero y no quiero

$y$ deliro y no deliro.

Una maravilla, no sé si de traducción, pero sí

de poema.

Y sobre esta preciosa falsilla escribo:

otra vez quiero

y no quiero y deliro

$y$ no deliro

Que es un haiku y — quizá- otro poema.

Que Anacreonte y Ferraté me perdonen.

Autor: Anacreonte de Teos · Traductor: Juan Ferraté

Traidor (quizá plagiario): J.A. Martínez Muñoz ${ }^{17}$

Se busca la originalidad, así, mediante la asimilación de otras voces; las ideas adquieren otro sentido al ser glosadas, levemente retocadas y situadas en un contexto distinto, y, a veces, a priori insólito. La mirada hacia la tradición grecolatina se engloba dentro de la ruptura y la innovación posmoderna. No se copia, se recontextualiza, y esto lleva consigo que estos modernos versos, aunque deudores y herederos de los antiguos, sean completa y totalmente otros. La tradición se presenta como una continuidad y evolución de géneros, tópicos y temas y viene marcada más por una necesidad que por una mera copia o imitación al más puro estilo renacentista. Hay todavía mucho que decir de aquello que ya se dijo. Existen aún muchas variables de significado en los textos clásicos, la tradición no deja de ser el pilar maestro en el que se asienta nuestra cultura y nuestro pensamiento y, por ende, nuestra literatura. No tendría entonces sentido alguno la permanencia de la tradición clásica en

16 J.L. Borges, "Pierre Menard, autor del Quijote", Ficciones, en: Obras completas, Barcelona, Círculo de lectores, 1992, vol. 2, p. 38.

17 J.A. Martínez Muñoz, "Ejercicio de traición”, Revista Hache, 1, 2004, p. 91. 
la lírica contemporánea, aunque dicha estabilidad temporal traiga consigo plagios, variantes, máscaras y recreaciones. Es, nuevamente, la idea borgiana del significado configurado como un conjunto de todas las lecturas posteriores:

Hamlet no es exactamente el Hamlet que Shakespeare concibió a principios del siglo XVII, Hamlet es el Hamlet de Coleridge, de Goethe y de Bradley. Hamlet ha sido renacido. [...] Los lectores han ido enriqueciendo el libro. Si leemos un libro antiguo es como si leyéramos todo el tiempo que ha transcurrido desde el día en que fue escrito y nosotros ${ }^{18}$.

El autor se ha convertido en aquello que siempre defendió el compositor francés Satie: "«Me llamo Erik Satie, como todo el mundo», [...] Ser Satie es ser irrepetible, esto es, encontrar un modo propio de disolverse hacia el triunfal anonimato, donde lo único es atributo de todos"19. En el cuento "La forma de la espada", Borges pone en boca de John Vincent Moon la siguiente afirmación: "Lo que hace un hombre es como si lo hicieran todos los hombres. [...] Acaso Schopenhauer tenga razón: yo soy los otros, cualquier hombre es todos los hombres, Shakespeare es de algún modo el miserable John Vincent Moon" 20 . No se reduce el poeta a una mera labor de arqueología literaria: se convierte en el hacedor de los versos. Leer a los demás y convertirlos en otros mediante palimpsestos ${ }^{21}$, puesto que "ningún poeta, ningún artista, posee la

18 J.L. Borges, "El libro", Borges oral, Madrid, Alianza Editorial, 1998, pp. 22-23.

19 J. Villoro, "La escritura desatada, Vila Matas rumbo a doctor Pasavento", en: M. Heredia (ed.), Vila-Matas portátil. Un escritor ante la crítica, Barcelona, Candaya, 2007, p. 362.

20 J.L. Borges, "La forma de la espada", Artificios, en: Obras completas, op. cit., vol. 2, p. 86. En otros relatos, Borges repite o reformula la misma idea: "Cualquier cosa es todas las cosas", leemos - como cita de Plotino - en "Acercamiento a Almotásim"; en "Los teólogos" se habla de un texto de Juan de Panonia que "no parecía redactado por una sola persona concreta, sino por cualquier hombre, o quizás, por todos los hombres", e idéntica concepción del Libro y el Autor encontramos en "La flor de Coleridge"; el comienzo de "La lotería de Babilonia" lo expresa de nuevo de manera especialmente poética: "Como todos los hombres de Babilonia, he sido procónsul; como todos, esclavo". Pero es quizá una nota a pie de página, en "Tlön, Uqbar, Orbis Tertius", la expresión más difundida de la idea: "Todos los hombres, en el vertiginoso instante del coito, son el mismo hombre. Todos los hombres que repiten una línea de Shakespeare, son William Shakespeare". J.L. Borges, "Acercamiento a Almotásim", Historia de la eternidad, en: ibidem, vol. 1, p. 453; "Los teólogos", El Aleph, en: ibidem, vol. 2, p. 145; "La flor de Coleridge", Otras Inquisiciones, en: ibidem, pp. 233-235; "La lotería de Babilonia", Ficciones, en: ibidem, vol. 2, p. 45; "Tlön, Uqbar, Orbis Tertius", Otras Inquisiciones, en: ibidem, vol. 2, p. 26.

${ }^{21}$ Quizá convendría preguntarnos sobre la autoría de "lo prestado" y enfrentarnos a un concepto superior, el de la autoría del poema. Hemos de volver sobre la afirmación filosófica de Nietzsche de que "Dios ha muerto", germen del pensamiento de la ideología posmoderna y factor ineludible en la "crisis de la autoría" y "la muerte del arte" prevista por Hegel, con la filosofía del lenguaje de Wittgenstein y con la "crisis del yo" de la Viena de fin-de-siècle, unidas a la posterior "muerte del autor" de deconstruccionistas como Roland Barthes, que reconoce que muchos de los cambios que venían desarrollándose en la sociedad y en el pensamiento influyen, directamente, en el arte y no pueden dejarse de lado en el análisis y la crítica del mismo. Cfr. R. Barthes "La muerte del autor", en: El susurro del lenguaje: más allá de la palabra y de la escritura, Barcelona, Paidós, 1994, pp. 68-69. Cfr. también F. Nietzsche, La gaya ciencia, Valencia, F. Sempere, 1920, p. 106; G.W.F. Hegel, Vorlesungen über die Ästhetik. 1. Die Idee und Das Ideal, Leipzig, Verlag von Feliz Meiner, 1931; L. Wittgenstein, Tractatus lógico-philosophicus, traducción, introducción y notas 
totalidad de su propio significado. Su significado, su apreciación, es la apreciación de su relación con los poetas y artistas muertos"22; toda escritura es, a fin de cuentas, una reescritura.

\section{Ejercicios de traición}

Pere Gimferrer (Barcelona, 1945), es también uno de los defensores del discurso concebido como generador de otros discursos: "escribo poesía por mimetismo. [...] mímesis no de la realidad sino de la cultura"23. Para Gimferrer, la inclusión de intertextos traducidos no deja de ser un sucedáneo alejado en alto grado del original. Enlaza esta reflexión metapoética ${ }^{24}$ con la marcada crisis nihilista de la escritura que compartirá con otros contemporáneos como es el caso de Antonio Martínez Sarrión (Albacete, 1939) y Guillermo Carnero (Valencia, 1947). Y sobre ello reflexiona en sus versos: sobre los problemas derivados de la poesía concebida como mímesis de la realidad. Tal es el caso de los dos poemas que cierran Extraña fruta $(1968)^{25}$ : "Antagonías" y este "Dido y Eneas",

I

Esta bien y es una norma: fuera del paraíso, recordando, no a Eliot, sino una traducción de Eliot, (nuestra vida como los pocos versos que quedan de T. E. Hulme) las naves que conducen a los guerreros difuntos, (qué dios, qué héroe bajo los cielos recibirá esta carga), la madera calafateada, el chapaleo las oscuras olas, avanzando, no hacia un reino ignorado, no hacia el recuerdo o la infancia,

de L.M. Valdés Villanueva, Madrid, Tecnos, 2002. Cfr. F. Jarauta, "Fin-de-siècle: ideas y escenarios", en: T. Rocha (ed.), Miscelánea vienesa, Cáceres, Universidad de Extremadura, Servicio de Publicaciones, 1998, pp. 29-36.

22 T.S. Eliot, "La tradición y el talento individual", en: La tradición y el talento individual, México, Universidad Nacional Autónoma de México, 2004, p. 66.

${ }^{23}$ P. Gimferrer, "Autopercepción intelectual de un proceso histórico. Itinerario de un escritor. (Discurso en el Ateneo)", Anthropos, 140, 1993, p. 21.

${ }^{24}$ La metaliteratura es una práctica poética de marcado carácter posmoderno y aunque comúnmente se la relaciona con el grupo de los novísimos, encontramos ejercicios metapoéticos en poetas anteriores como es el caso de José Ángel Valente. Los procesos metapoéticos han de ser entendidos como reflexiones que buscan una renovación, una determinada transformación de la lírica, una tarea en cierto modo higiénica y purificadora. La crisis por la que transitaba la poesía a finales de los sesenta, paralizada por la temática inamovible del realismo social, desembocó en una introspección metapoética que es concebida no solo como una búsqueda teórica sobre la poesía, sino también como declaración de principios y como crítica o autocrítica, podemos hablar incluso de los poemas metaliterarios como verdaderas poéticas personales. Cfr. L. Sánchez Torre, La poesía en el espejo del poema. La práctica metapoética en la poesía española del siglo XX, Oviedo, Universidad de Oviedo, Departamento de Filología Española, 1993, pp. 134-140.

${ }^{25}$ Se escribió entre enero y junio de 1968 y finalmente apareció recogido en P. Gimferrer, Poemas 1963-1969, Barcelona, Ocnos, 1969. 
sino más bien hacia lo conocido. Así vuelve de pronto Milán, una noche, a los dieciséis años: luz en la luz, relámpago, rosa y cruz de la aurora (los tranvías, disueltos en el crepúsculo, de oro, de oro y en mi pecho qué frágiles)

Dido y Eneas, sólo una máscara de nieve, un vaciado en yeso tras el maquillaje escarlata, como danzarina etrusca, cálido fox, oscuro petirrojo, la imperial de los ómnibus de Nueva Orleans está pintada de amarillo y hay que bailar con un alfiler de oro en la mejilla (como cuando se rezan oraciones para conjurar al Ruiseñor y la Rosa o al milano en la tarde)

Amor mío, amor mío, dulce espada, las llamas invadieron las torres de Cartago y sus jardines, qué concierto en la nieve para piano qué concierto en la nieve ${ }^{26}$.

No estamos, como pudiera parecer, ante un poema que desarrolle el tema virgiliano, sino ante una compleja reflexión metapoética que se glosa en todo el volumen de Extraña fruta ${ }^{27}$. Gimferrer exprime la línea experimentalista iniciada con anterioridad en La muerte en Beverly Hills. Aun siendo un poemario más fraccionario, en el que los discursos se superponen confundiendo al lector, mantiene los mismos pilares básicos que conforman su poesía. Se cuestiona Gimferrer dónde se encuentran los márgenes entre la realidad y el poema; qué queda de verdad en la palabra en el marco ficcional que encierra todo el texto poético: "El poeta se replantea el sentido y los porqués de su obra. [...] La meditación aparece haciéndose, de manera que cada poema es a la vez que su realización una pregunta sobre sí mismo y su significado. La poesía como tema del poema y el lenguaje como trampa a que debe escapar el poeta son los ejes" 28 . Las figuras míticas de Dido y Eneas ${ }^{29}$ no son más que "un vaciado de yeso tras un maquillaje escarlata", "una máscara de nieve" tras la que esconderse, pero solo momentáneamente por su inconsistencia. El poeta se enfrenta, una vez más, a la dura constatación de la artificialidad del lenguaje y de su no representatividad de la realidad. El lenguaje, y con él la palabra poética, son entidades arbitrarias. La palabra es un arte imitativo que no aprehende la esencia de la materialidad en sílabas y letras. Es la evolución natural del viejo problema platónico: el problema de la inexactitud del lenguaje y de la exactitud de los nombres (orthótēs onomátōn). La extrapolación

${ }^{26}$ Ibidem, p. 144.

${ }^{27}$ No existe una edición exenta del libro, se recoge en: P. Gimferrer, Poemas 1963-1969, op. cit.

28 J. Talens, "Reflexiones en torno a la poesía última de P. Gimferrer", Ínsula, 304, 1972, p. 15.

${ }^{29}$ Existe un estudio bastante exhaustivo, de Vicente Cristóbal López, sobre la presencia de Dido y Eneas en la literatura española. Cfr. V. Cristóbal López, "Dido y Eneas en la literatura española", Alazet. Revista de Filología, 14, 2002, pp. 41-76. 
de la antinomia sofista de physis/nómos. Siguiendo la teoría convencionalista defendida por Hermógenes en el Crátilo de Platón ${ }^{30}$ : la palabra no nos proporciona una información exacta de la realidad, conociendo la palabra no se accedería al logos de lo nombrado. Nos enfrentamos a un vacío ontológico, a una experiencia poética tendente a negar paradójicamente el lenguaje. La historia de amor que sirvió de disculpa a Virgilio para escribir el libro IV de la Eneida ${ }^{31}$ no será representada plenamente a través de la lengua; nunca serán capaces las palabras de manifestar toda la plenitud vital de esa relación amorosa. El lenguaje no es solo el que se concibe como artificio, la historia sentimental también se representa en espectáculos musicales, como Dido y Eneas de Purcell, referida en el poema en esa "máscara de nieve", que vuelve a traer a colación la doble quimera de la transducción. Refuerza Gimferrer la idea de la vacuidad del sentimiento amoroso al traer a colación los recuerdos del yo lírico (Nueva Orleans, Milán). Es precisamente esta evocación estética y personal comparada con la poesía, su rareza y su fragilidad ("nuestra vida como los pocos versos que quedan de T. E. Hulme"), la que pone de manifiesto la problematización de la relación entre la vida y el lenguaje poético. Para Vicente Vives Pérez "tanto el emblema culturalista como la metapoesía suponen una misma crítica del lenguaje convencional y de aquellos elementos poéticos mitificados desde el Romanticismo" 32 . Pero en Gimferrer no nos enfrentamos a un nihilismo ad hoc, como el que sí puede observarse en la poesía de su coetáneo Martínez Sarrión, nos centramos más en otro -ismo, el del escéptico ${ }^{33}$ : “¿qué costa? ¿Qué legiones?”, amparado por una esperanza asentada en el armazón, en la artesanía del poema, en la retórica: "y aún nos es posible cierta aspiración al equilibrio / la pureza de líneas, / el trazado de un diseño, / el olvido de la retórica de lo explícito por la retórica de las alusiones, / los recursos del arte (la piedra presiente la forma)" ${ }^{34}$. La retórica culturalista de las alusiones nos lleva a la cita de Eliot mencionada al inicio del poema ${ }^{35}$. Desconfía del lenguaje, de la posibilidad de conseguir una experiencia directa. La fractura palpable entre arte y vida ${ }^{36}$. Al cantar los amores de Dido y Eneas estamos contaminando la integridad de su relación. No se recuerda a Eliot,

${ }^{30}$ Platón, "Crátilo", Diálogos, vol. 2, traducción introducción y notas de J. Calonge Ruiz, Madrid, Gredos, 1983.

${ }^{31}$ P. Virgilio Marón, Eneida, ed. de J.C. Fernández Corte, Madrid, Cátedra, 1993.

${ }^{32}$ V. Vives López, "Claves temáticas de la poesía posmoderna española", Revista de Literatura, 150, 2013, pp. 597-598.

${ }^{33}$ Un escepticismo que ya había mostrado las interrogaciones a las que se sometía el poeta en poemarios anteriores. Así en "Julio de 1965”, del poemario Arde el mar podemos leer: “¿Es verdad lo que escribo?" o "Tanto he escrito y tanto escribí. No sé / si valía la pena o vale". P. Gimferrer, Arde el mar, Barcelona, El Bardo, 1966.

34 C.G. Moral, R.M. Pereda (eds.), Joven poesía española, Madrid, Cátedra, 1979, p. 194.

${ }^{35}$ La presencia de Eliot en los poetas contemporáneos es recurrente. Así puede verse en el trabajo de Ioana Gruia, Eliot y la literatura del tiempo en la poesía española contemporánea, Madrid, Visor, 2009.

${ }^{36}$ Cfr. A.L. Prieto de Paula, Musa del 68. Claves para una generación poética, Madrid, Hiperión, 1996, pp. 103-130. 
sino una traducción de Eliot como símil de la palabra, un sucedáneo de lo real, que nunca llegará a rozar la totalidad de su esencia. Del poeta inglés se intertextualizarán varios versos más: "las llamas invadieron las torres de Cartago y sus jardines", que en Eliot se lee: "To Carthage then I came / burning, burning, burning, burning" 37 , del poema "El sermón del fuego"; "qué costas y escolleras", del poema "Marina" de Eliot: "What seas what shores what grey rocks and what islands What water lapping the bow"38.

\section{II}

Y aún nos es posible cierta aspiración al equilibrio,

la pureza de líneas, el trazado de un diseño,

el olvido de la retórica de lo explícito por la retórica de las alusiones,

los recursos del arte (la piedra presiente la forma),

el recuerdo de una tarde de amor o un rezo en la capilla del colegio,

la vidriera teñía los rostros de un esplendor violeta,

naufragaban en la claridad submarina las hebillas de oro de los caballeros

todo en escorzo, la luz amarilla chorreando en las botas y los cintos,

las cabezas estáticas, vueltas al cielo raso, porcelana en la tarde,

la quilla, los velámenes,

(qué costas y escolleras),

las islas, timonel,

en el viento nos llegan los cabellos de una sirena, las arenas doradas

historias de hombres ahogados en el mar.

¿qué costa? ¿Qué legiones? ${ }^{39}$

El poema y la palabra, concebida como diosa Gea, se ven simbolizados en el reflejo etéreo de una vidriera, que al paso de la luz efímera da vida a una historia de caballeros, barcos y sirenas. La palabra al igual que el haz de luz no puede más que ser un reflejo luminoso de la realidad, a la que imita con sus colores y viveza pero de la que no es más que una manifestación sutil y pasajera. Juan Ferrater lo explica así,

en principio toda poesía es oblicua, toda poesía traspone los términos usados a un plano que podríamos llamar de ficción en contraposición al uso denotativo real del habla normal. Toda realidad representada en el poema ingresa en un orbe de significación donde los caracteres objetivos que la cosa pueda tener no importan como realidades, sino solo y en la medida en que valen para la unidad del sentido del poema. Esto significa que los términos usados no tienen una función denotativa real (actual o potencial), sino solo pretendida, fingida, y nunca cumplida en la realidad ${ }^{40}$.

${ }^{37}$ Los versos iniciales (To Carthage then I came) los toma Eliot de San Agustín. Se trata de la frase con que se inicia el libro tercero de Las Confesiones (Veni Carthaginem), coincidiendo con la llegada del santo a la ciudad mediterránea a finales del año 370. San Agustín, Confessionum, El Escorial, Nova editio critica, Imp. Real Monasterio, 1930, 3.1.1. T.S. Eliot, The complete poems and plays of T.S. Eliot, London, Faber and Faber, 1969, p. 70.

38 T.S. Eliot, op. cit., pp. 109-110.

39 C.G. Moral, R.M. Pereda (eds.), op. cit., p. 194.

40 J. Ferrater, "Lingüística y poética", en: F. Cabo (ed.), Teorías de la lírica. Madrid, ArcoLibros, pp. 160-161. 
Gimferrer apela a la esterilidad de la literatura cuando se osa ir más allá de lo ficcional, cuando se pretende insuflar aliento vital al reflejo vitral; la literatura alude, pero no es. Estamos ante una vuelta más del horaciano ut pictura poesis $^{41}$, la representación figurativa en una vidriera no es más que mímesis, no esencia, reflejo brillante que se vuelve tenue hasta desaparecer, imagen reflejada que no puede ser aprehendida, como las palabras en un poema. El conocido desajuste de la traducción ("recordando, no a Eliot, sino una traducción de Eliot") puede verse representado en ese intento mimético de trasladar la vida a la imagen de la vidriera, la vida a la palabra poética, más cuando nos enfrentamos a naturalezas distintas. Especialmente porque la principal entidad del lenguaje, su referencialidad, implica que este trata de ser "traducción" en signos verbales de la realidad, pero es imposible corresponder biunívoca, satisfactoria y sin confusiones entre las realidades y los signos (las palabras y las cosas) y Gimferrer es consciente de este drama y en torno a él articula toda su poesía ${ }^{42}$.

La confesión del Gimferrer de antes de los setenta, cuando dice haber escrito kitsch; haber recordado no a Eliot, sino una traducción de Eliot; no haber escrito sino sólo reescrito, es una buena muestra de la conciencia que existía en algunos novísimos de entonces sobre lo que suponía el manejo de una cultura al final de las culturas ${ }^{43}$.

El nihilismo latente en la poética de los novísimos debe ser entendido como una forma de actualización y reinterpretación de la verdad estética y la naturaleza artística.

\section{Conclusiones}

Los metapoemas se conciben, pues, como una búsqueda de conocimiento estético a través de la palabra. Sirven para reflexionar sobre la incapacidad del lenguaje a la hora de expresar experiencias personales y constatan el fracaso de la palabra poética cuando se intenta comunicar la realidad: "La imagen que el arte devuelve procede de la vida, pero no es ya la vida"44. Nos enfrentamos a un conjunto de elegías poéticas del exilio del verbo y la palabra. En ellas se niega la comunicación lírica, siempre dentro de los parámetros de la inutilidad y las limitaciones del lenguaje, reafirmando que la poesía no puede pretender

${ }^{41}$ Horacio, Arte poética, Cáceres, Universidad de Extremadura, 1998, v. 361 y ss.

${ }^{42}$ Nos remiten estos pensamientos a Magritte y su "Ceci n'est pas une pipe" o a Foucault y su Les mots et les choses, una lectura fundamental en esta época. M. Foucault, Les mots et les choses. Une archéologie des sciences humaines, Paris, Gallimard, 1966.

${ }^{43}$ F. Rodríguez de la Flor, "Neo-neo-clasicismos en la poesía española última", Los cuadernos del Norte, 20, 1983, p. 64.

44 J.L. Rey, Caligrafía del fuego, la poesía de Pere Gimferrer 1962-2001, Valencia, PreTextos, 2005, p. 158. 
comunicar una experiencia a través de la palabra. Esta imposible conciliación en el proceso poético de la vida y el verbo deriva en una paradójica negación del poema, puesto que el verso está intentando comunicar estas cuitas estéticas y mostrar un nihilismo poético que exilia al poeta ("fuera del paraíso", "qué dios, qué héroe bajo los cielos recibirá esta carga"). No obstante, Gimferrer está haciendo poesía; el trabajo de escritura encuentra su norte en el hecho mismo de hacerla, de cantar en un himno la actualización constante de la lírica a la que accedemos a través de la reflexión poética.

\section{Referencias bibliográficas}

BARTHES R.

1994 "La muerte del autor", en: El susurro del lenguaje: más allá de la palabra y de la escritura, Barcelona, Paidós, pp. 65-71.

BERGUA CAVERO J.

2003 "La tradición clásica y el concepto de influencia", en: Fernández Ariza G. (ed.), Literatura Hispanoamericana del siglo XX. Mímesis e iconografía, Málaga, Servicio de Publicaciones de la Universidad de Málaga, pp. 11-21.

BORGES J.L.

1992 Obras completas, Barcelona, Círculo de lectores, 4 vols.

1998 "El libro", Borges oral, Madrid, Alianza Editorial, pp. 9-23.

BOURDIEU P.

1997 Razones prácticas. Sobre la teoría de la acción, Barcelona, Anagrama.

CARNERO G.

2005 "Cuatro formas de culturalismo", Poesía española contemporánea, Alicante, Biblioteca Virtual Miguel de Cervantes, <http://www.cervantesvirtual.com/obra-visor/cuatro-formas-de-culturalismo-0/pdf $>10$ de marzo de 2016.

CRISTÓBAL LÓPEZ V.

2002 "Dido y Eneas en la literatura española", Alazet. Revista de Filología, 14, pp. 41-76.

DÍAZ DE CASTRO F.

2010 "La tradición clásica en la poesía española reciente: aproximaciones", en: Naval M.A.

ELIOT T.S. (ed.), Poesía española posmoderna, Madrid, Visor, pp. 63-99.

1969 The complete poems and plays of T. S. Eliot, London, Faber and Faber, 1969.

2004 "La tradición y el talento individual", en: La tradición y el talento individual, México, Universidad Nacional Autónoma de México, pp. 63-81.

FERNÁNDEZ MALLO A.

2012 Blog up, ed. de T. Gómez Trueba, Valladolid, Universidad de Valladolid, Secretariado de Publicaciones e Intercambio Editorial.

FERRATER J.

1999 "Lingüística y poética”, en: Cabo F. (ed.), Teorías de la lírica, Madrid, Arco-Libros, 1999, pp. 155-173.

\section{FOUCAULT M.}

1966 Les mots et les choses. Une archéologie des sciences humaines, Paris, Gallimard. GARCÍA GUAL C.

2001 "Cultura clásica y mundo actual”, en: Ribot García L. A., Villares Paz R., Valdeón Baruque J. (eds.), Año mil, año dos mil. Dos milenios de Historia de España (II), Madrid, Sociedad Estatal España Nuevo Milenio, pp. 253-266. 


\section{GIMFERRER P.}

1966 Arde el mar, Barcelona, El Bardo.

1969 Poemas 1963-1969, Barcelona, Ocnos.

1993 "Autopercepción intelectual de un proceso histórico. Itinerario de un escritor. (Discurso en el Ateneo)", Anthropos, 140, pp. 19-31.

\section{GRUIA I.}

2009 Eliot y la literatura del tiempo en la poesía española contemporánea, Madrid, Visor.

\section{HASSAN I.}

1978 "Culture, Indeterminancy and Immanence: Margins of the (Postmodern) Age", Humanities in Society, 1, pp. 51-85.

1980 The Right Promethean Fire: Imagination, Science and Cultural Change, Urbana, University of Illinois Press.

1986 "Pluralism in Postmodern Perspective", Critical Inquiry, vol. 12, 3, pp. 503-520.

HEGEL G.W.F.

1931 Vorlesungen über die Ästhetik. 1. Die Idee und Das Ideal, Leipzig, Verlag von Feliz Meiner.

\section{HORACIO}

1998 Arte poética, Cáceres, Universidad de Extremadura.

JARAUTA F.

1998 "Fin-de-siècle: ideas y escenarios", en: Rocha, T. (ed.), Miscelánea vienesa, Cáceres, Universidad de Extremadura, Servicio de Publicaciones, pp. 29-36.

\section{LAGUNA MARISCAL G.}

2001 "La influencia de la poesía latina en la española durante el Renacimiento", en: Actas de las II Jornadas de Humanidades Clásicas, Almendralejo (Badajoz), I.E.S. Santiago Apóstol D. L., pp. 40-50.

LÁZARO CARRETER F.

1979 "Imitación compuesta y diseño retórico en la Oda a Juan de Grial", Anuario de Estudios Filológicos, 2, pp. 89-119.

LYOTARD J.F.

1977 Les transformateurs Duchamp, Paris, Éditions Galilée.

MARTÍNEZ MUÑOZ J.A.

2004 "Ejercicio de traición", Revista Hache, 1, p. 91.

MENDOZA FILLOLA A.

2001 El intertexto lector. El espacio de encuentro de las aportaciones del texto con las del lector, Cuenca, Ediciones de la Universidad de Castilla la Mancha.

MORAL C.G., PEREDA R.M. (eds.)

1979 Joven poesía española, Madrid, Cátedra.

NIETZSCHE F.

1920 La gaya ciencia, Valencia, F. Sempere.

PLATÓN

1983 "Crátilo", Diálogos, vol. 2, traducción, introducción y notas de J. Calonge Ruiz, Madrid, Gredos, pp. 339-461.

PRIETO DE PAULA Á.L.

1996 Musa del 68. Claves para una generación poética. Madrid, Hiperión.

\section{REY J.L.}

2005 Caligrafía del fuego, la poesía de Pere Gimferrer, 1962-2001. Valencia, Pre-Textos.

RODRÍGUEZ DE LA FLOR F.

1983 "Neo-neo-clasicismos en la poesía española última", Los cuadernos del Norte, 20, pp. 61-65.

\section{SAN AGUSTÍN}

1930 Confessionum, El Escorial, Nova editio critica, Imp. Real Monasterio. 


\section{SÁNCHEZ TORRE L.}

1993 La poesía en el espejo del poema. La práctica metapoética en la poesía española del siglo $X X$, Oviedo, Universidad de Oviedo, Departamento de Filología Española.

\section{SARESBERIENSIS I.}

1991 Metalogicon, ed. de J.B. Hall, auxiliata K.S.B. Keats-Rohan, Turnhout, Brepols.

\section{TALENS J.}

1972 "Reflexiones en torno a la poesía última de P. Gimferrer", Ínsula, 304.

VÁSQUEZ ROCA A.

2004 "El hipertexto y las nuevas retóricas de la postmodernidad. Textualidad, redes y discurso ex-céntrico", Philosophica. Revista del Instituto de Filosofía, Universidad Católica de Valparaíso, 27, pp. 331-350.

VILLORO J.

2007 "La escritura desatada, Vila Matas rumbo a doctor Pasavento", en: Heredia M. (ed.), VilaMatas portátíl. Un escritor ante la crítica, Barcelona, Candaya, pp. 361-366.

VIRGILIO MARÓN P.

1993 Eneida, ed. de J.C. Fernández Corte, Madrid, Cátedra.

VIVES PÉREZ V.

2013 "Claves temáticas de la poesía posmoderna española", Revista de Literatura, vol. LXXV, 150 , pp. 593-622.

WALSH G.

1989 "Epílogo", en: Kenney E.J., Clausen W.V. (eds.), Historia de la Literatura Clásica, Vol. II, Literatura Latina, Madrid, Gredos, pp. 849-855.

\section{WITTGENSTEIN L.}

2002 Tractatus lógico-philosophicus, traducción, introducción y notas de L.M. Valdés Villanueva, Madrid, Tecnos.

\section{Exercises in treason: Intertextuality, culturalism and translation in Spanish contemporary poetry}

Keywords: intertextuality — translation - appropriation - metapoetry — postmodernism — culturalism — Spanish contemporary poetry.

\section{Abstract}

Though the classical influence and the culturalist poetry cannot be reduced solely to the use of transtextual procedures, this practice represents a device that fits perfectly within the poetic uses; it helps to build the aesthetic inherent to the postmodern thought; and it is raised as the principal representative of this poetic style. In this succinct approach, two metapoetic reflections on the inclusion of intertexts are shown as a paradigm, to make clear that the positions of the poets against intertextuality are mixed, but are equally successful in the postmodern ideology in which much of the production of contemporary Spanish poetry is included. 